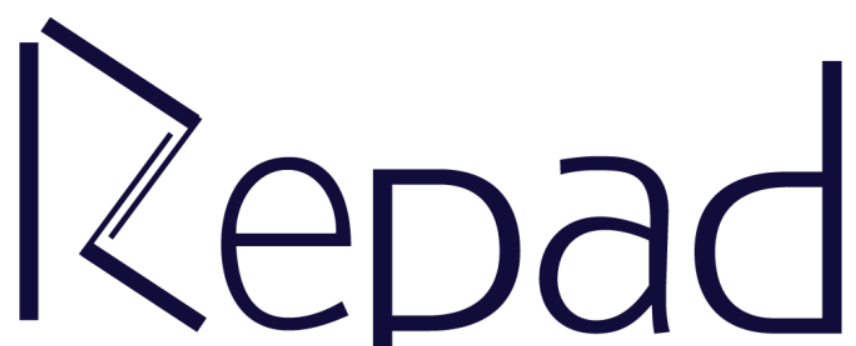

v. 5, n. 1, Janeiro-Abril/2021

Revista Estudos e

Pesquisas em Administração

(c) (i) This work is licensed under a Creative Commons Attribution 4.0 International License 


\title{
A controversa transparência dos portais eletrônicos governamentais
}

\author{
Kristinne Kelly Rosa Borges Vaz \\ https://orcid.org/0000-0002-7007-7068 \\ Universidade do Sul de Santa Catarina - Unisul \\ Florianópolis, Santa Catarina, Brasil \\ Cristina Martins \\ https://orcid.org/0000-0001-8635-0981 \\ Universidade do Sul de Santa Catarina - Unisul \\ Florianópolis, Santa Catarina, Brasil \\ Jacir Leonir Casagrande \\ https://orcid.org/0000-0002-2668-1065 \\ Universidade do Sul de Santa Catarina - Unisul \\ Florianópolis, Santa Catarina, Brasil \\ Sandro Vieira Soares \\ sandrovieirasoares@hotmail.com \\ https://orcid.org/0000-0001-7076-4936 \\ Universidade do Sul de Santa Catarina - Unisul \\ Florianópolis, Santa Catarina, Brasil
}

\section{RESUMO}

Esta pesquisa teve como objetivo mapear as produções científicas sobre transparência em portais eletrônicos governamentais. Para tal, utilizou-se da estratégia bibliográfica, acrescentando-se indicadores comumente utilizados na bibliometria. A análise foi realizada numa amostra composta de 55 artigos, publicados nas bases de dados internacionais DOAJ, Redalyc, Scopus, Scielo e Spell. Dentre os principais resultados, evidenciaram-se níveis inexpressivos de transparência, prejudicando o controle social e fiscal por parte da sociedade, além da falta de consenso na aplicação de metodologias sobre transparência, culminando em uma diversidade considerável de índices. Ademais, os estudos demonstraram concentração em níveis municipais, o que sugere lacuna científica quanto às esferas federal e estadual de governo, caracterizando oportunidades de pesquisa.

Palavras-chave: Transparência. Administração pública. Portais eletrônicos. Indicadores. Sociedade.

\section{Controversial transparency of governamental websites}

\begin{abstract}
This research aimed at mapping scientific productions about transparency in government electronic portals. To this end, we used the bibliographic strategy adding indicators commonly used in bibliometrics. The analysis carried out on the sample of 55 papers published in the international databases DOAJ, Redalyc, Scopus, Scielo and Spell. Among the main results, there were inexpressive levels of transparency, impairing social and fiscal control by society; lack of consensus in the application of
\end{abstract}


methodologies on transparency culminating in a considerable diversity of indexes. In addition, studies have shown concentration at municipal levels, which suggests a scientific gap in the federal and state spheres of government, characterizing research opportunities.

Keywords: Transparency. Public administration. Websites. Indicators. Society.

Submetido: 04/01/2021

Aceito: 28/01/2021

Publicado: 30/04/2021

\section{INTRODUÇÃO}

A busca, nos últimos anos, pela adoção de boas práticas de governança na administração pública tem exigido uma gestão mais transparente e estimulado o controle social na aplicação dos recursos públicos (MORAIS; GUERRA, 2016). Assim, a transparência pública ultrapassa as fronteiras da área legal/fiscal e incorpora outras questões, tal como desempenho pessoal, controles internos, etc. (BAIRRAL; SILVA; ALVES, 2015).

Na concepção de Nunes et al. (2013), a sociedade está entrando em um novo estágio de entendimento quanto ao processo de fiscalização da administração pública, exigindo mais transparência dos gestores, nas ações realizadas com recursos públicos. Nessa linha, Meijer (2009) destaca a concepção de transparência como base primordial da democracia representativa, que propicia ao povo monitorar seus representantes, e que vem avançando de forma a permitir que as pessoas participem do domínio público.

Conforme Salgado e Aires (2017), a temática em questão tem alcançado lugar nas discussões científicas, com a publicação, nos últimos anos, de artigos que, entre outros pontos, têm analisado, em diferentes realidades ou esferas públicas, se a transparência e a participação democrática têm sido proporcionadas pelos sítios eletrônicos. Desse modo, os estudos no contexto da transparência em portais eletrônicos, nas suas diferentes esferas (Federal, Estadual e Municipal), podem demonstrar um importante mecanismo de monitoramento de recursos públicos.

Ante essas considerações, emerge o seguinte questionamento: quais são as produções científicas em pesquisas relacionadas à transparência em portais eletrônicos governamentais? Posta a interrogação, para responder a questão de pesquisa, estabeleceu-se como objetivo geral: mapear as produções científicas em bases de dados internacionais e nacionais sobre transparência em portais eletrônicos governamentais até o ano de 2020.

Estudos dessa natureza vêm se efetivando como um método rigoroso na pesquisa científica, não só no formato de quantificação da produção científica, a partir de indicadores comumente usados na bibliometria (SOARES; PICOLLI; CASAGRANDE, 2018), mas também através de aplicações mais abrangentes e aprofundadas, tal como neste artigo, a partir da análise de qualidade, atividades e impactos científicos, além das agregações temáticas (BEIRA et al., 2020).

O presente artigo está estruturado em cinco seções além dessa, Introdução: seção 2 - revisão de literatura; seção 3 - procedimentos metodológicos; seção 4 - análise dos resultados e discussão e; seção 5 - considerações finais, seguida das referências. 


\section{REVISÃO DA LITERATURA} questão.

Apresentam-se, nesta seção, conceitos ou teorias que fundamentam o artigo em

\section{Transparência na Administração Pública}

A transparência, apesar de não ser um dos princípios mencionados no art.37 da Constituição Federal, abrange um caráter mais amplo, pois, ao mesmo tempo em que se relaciona com a publicidade, também se relaciona com o direito à informação do cidadão. Assim, a publicidade (divulgação) e informação conjugam-se, fazendo emergir o conceito de transparência. Segundo Nunes et al. (2013), a transparência expressa o sentido de algo que se nota facilmente, que está nítido, translúcido. Nessa acepção, as ações realizadas pela administração pública, por meio dos seus agentes públicos, devem ser conhecidas de toda sociedade.

Nessa linha, Cruz, Silva e Santos (2009) entendem que a transparência deve evidenciar as atividades realizadas pelos gestores públicos, de forma que o cidadão possa compreender o que está sendo realizado, a partir do poder de representação que foi para eles concedido. A transparência é determinada pela perspectiva legal, através do arcabouço jurídico existente na Constituição Federal de 1988 , no art. $5^{\circ}$, incisos XXXIII, XXXIV e LXXII, e, implicitamente, no art. 37, que expressa exigências de transparência de informações por parte da administração pública (CRUZ et al., 2012). O alicerce da transparência está na responsabilização das ações dos gestores, especificamente descrita no art. 48 da Lei de Responsabilidade Fiscal - LRF, que trata dos instrumentos de transparência fiscal, os quais preveem mecanismos de transparência da gestão fiscal em meio eletrônico de acesso público.

Ainda, na análise de Cruz et al. (2012), a partir da LRF, a transparência da gestão fiscal no Brasil passou a ser uma exigência legal, dando subsídios à fiscalização tanto pelos órgãos competentes, como, também, pela população. Contudo, deve-se esclarecer, a gestão transparente não pode se limitar a agir somente como um dispositivo de divulgação da transparência fiscal, devendo alarga-se à materialização do conceito de accountability, quando proporciona aos cidadãos oportunidade de conhecer e participar, realmente, das ações da administração pública, que impactam em toda a sociedade.

Nesse sentido, ressalta-se ainda que, embora a transparência esteja diretamente vinculada à publicidade (CRUZ et al., 2012), as informações não podem limitar-se a relatórios definidos no arcabouço legal existente; mais que isso, devem observar e disponibilizar as informações qualitativas que demonstrem o desempenho, os projetos e as ações voltados para as diversas áreas de atuação da administração pública (educação, saúde, cultura, saneamento, segurança e outras), para a sociedade. Em linha semelhante, Nunes et al. (2013), Gama e Rodrigues (2016) citam que a transparência, através do acesso aos atos públicos, é ferramenta fundamental para que a sociedade tenha maior controle dos atos da gestão pública, refletindo, ato contínuo, em maior consciência dos seus direitos e do processo da gestão pública de forma geral, ou seja, por meio das informações mais transparentes e comparáveis, especificamente quanto às informações de natureza contábil, consegue-se convergir a normas e padrões internacionais no setor público.

Em complemento, Pires et al. (2013) observam que o fomento da transparência é o alvo principal da moderna administração pública. A expansão do ato de divulgar as 
ações governamentais para a população contribui para a consolidação da democracia, além de ampliar a noção de cidadania, já que o conhecimento desses dados e informações propicia aos cidadãos fiscalizar o gasto de dinheiro público, avaliar as decisões orçamentárias e combater a corrupção (NEBOT, 2019). Vale lembrar, nesse sentido, que a transparência resulta da medida de relação entre informação, comunicação e interação entre a sociedade e o estado.

Conforme Melo e Fuchigami (2019), uma gestão pública com transparência exige responsabilidade quanto aos bens e recursos públicos, e está vinculada ao fornecimento de justificativas, bem como fica sujeita às penalidades. Cabe, portanto, à gestão pública criar meios que possibilitem uma ativa "participação social" nas ações governamentais ((re)planejamento e tomada de decisão) do Estado, buscando discussões sobre questões sociais relevantes para implementação de políticas públicas.

Na concepção de Robles-López e Zamora-Medina (2020), a compreensão sobre o que é a organização pública será mais clara se os cidadãos tiverem possibilidade e facilidade de acessar e entender as informações, permitindo que haja, nesse caso, bidirecionalidade. Assim, se a gestão pública não for realizada de forma otimizada, será impossível responder às demandas sociais de transparência e excelência no atendimento público, oferecido pelos governos locais. Cruz e Zuccolotto (2020) apontam que existe um processo cíclico que abrange transparência, accountability e democracia, visto que sem transparência não pode haver accountability e, consequentemente, democracia. Diante do exposto, confirma-se a importância de se compreender acerca dos meios de divulgação de informações, especificamente a partir de portais eletrônicos, foco deste estudo.

\section{Meios de Divulgação: Portais Eletrônicos}

Nos últimos anos, vem-se constatando a importância do governo eletrônico para a administração pública. Assim, conforme afirmam Diniz, Machado e Matos (2016), a transparência digital implica a utilização de Tecnologias de Informação e Comunicação (TIC) e do conceito de governo eletrônico, de forma a propiciar novos meios de interação/integração entre agentes públicos e sociedade.

Segundo Prado e Loureiro (2006), o governo eletrônico surgiu da conjuntura de reforma do Estado e do afloramento de temas como accountability e transparência, trazidos pelo advento de novas tecnologias na área da informática, que permitiram não só a criação de sistemas de informação, mas também o avanço da microinformática e da internet. Destarte, para Diniz, Machado e Matos (2016), entendem que o domínio acerca de várias possibilidades de uso da internet pelo governo pode tornar a gestão pública mais transparente, e representa um ensaio no conhecimento da tecnologia para o desenvolvimento de serviços e informações voltados à população.

Com vista à divulgação das informações, utilizar tecnologias voltadas para disseminação da informação tem se tornado alvo de aprimoramento por parte do setor governamental. Ainda nesse enfoque, Pires et al. (2013) acrescentam que a utilização de tecnologias voltadas às ações de governo se concretiza pelo que se chama de $E$ government ou governo eletrônico, representada pela informatização de suas atividades internas e pela comunicação que ocorre, de forma interna, entre os órgãos públicos, e o público externo (fornecedores, empresas, cidadãos) e toda a sociedade. Nesse contexto, entende-se que a informatização está apoiada no desenvolvimento de portais governamentais, nos quais o poder público pode apresentar suas intenções, ações e 
realizações, além de possibilitar a aglutinação e disponibilização de serviços e informações aos cidadãos (PIRES et al., 2013).

Em contraponto, os mesmos autores, Pires et al. (2013), alertam que elementos como os citados por Diniz et al. (2016) não esgotam os objetivos dos governos eletrônicos, que incluem a transparência e a participação da sociedade nas ações governamentais. Alertam, ainda, que é necessário evidenciar que os planos, as diretrizes, e as ações governamentais devem ser transparentes para a sociedade, uma vez que a gestão das atividades públicas é executada com recursos mantidos pela população. Assim, sugerem que a administração pública pode proporcionar acesso à população através de mecanismos tecnológicos, de forma a deixar transparente a gestão fiscal e administrativa, visando apartar os obstáculos que possam dificultar o pleno conhecimento da informação por parte daqueles sobre quem o poder é exercido.

Todavia, para Diaz et al. (2019), embora a inovação da estrutura tradicional tenha se modernizado, o 'Electronic' ainda não causou uma ação de envolvimento dos cidadãos na tomada de decisão, motivo pela qual vê-se a necessidade de criar um novo paradigma, que considere em seus pilares a transparência, a participação e a colaboração, para melhorar a democracia. Consequentemente, os processos e as tarefas da administração pública devem estar abertos para a cidadania, a fim de ser assegurada alternativa para a melhoria da transparência. Com essas considerações, passa-se a discorrer sobre os caminhos seguidos na construção deste estudo.

\section{PROCEDIMENTOS METODOLÓGICOS}

Esta pesquisa é identificada como descritiva de caráter exploratório, com a utilização de abordagem mista, estratégia bibliográfica com apoio de indicadores, comumente aplicados na bibliometria. Para tal, considerando a importância, confiabilidade e difusão das publicações em nível internacional, selecionou-se as bases de dados: DOAJ, Redalyc, Scopus, Scielo e Spell.

Em seguida, realizou-se um pré-teste nas bases de dados com a finalidade de identificar palavras-chave que gerassem resultados mais expressivos, tendo sido selecionadas as seguintes palavras-chave aplicadas em inglês - transparency electronic portals; website transparency; digital transparency; transparency index; transparency indicators - resultando um retorno de 96 artigos.

Cabe lembrar que, por se trabalhar com diferentes bases de dados, não se optou por delimitar o tempo inicial para consulta, apenas um limite final, que correspondeu ao mês da coleta de dados realizado, no caso, julho e outubro de 2020.

Uma vez obtidos os resultados, iniciou-se um processo de refinamento através de uma leitura prévia dos títulos e resumos de cada publicação. Com essa análise preliminar, foram eliminados 18 (dezoito) artigos em duplicidade; 23 (vinte três) não foram considerados alinhados ao objetivo da presente pesquisa, por abordar objetivos divergentes ao foco delimitado, como a construção da accountability, medição de índice de governança, e análise do comportamento informacional de cidadãos.

Com isso, a amostra final do estudo para aplicação de análise mais aprofundada foi composta pelos 55 (cinquenta e cinco) artigos restantes, os quais, além de alinhamento ao tema, não eram duplicados, conforme apresenta-se na Tabela 1. 
Tabela 1. Resultado das etapas de refinamento, aplicadas na pesquisa

\begin{tabular}{l|c|c|c|c}
\hline $\begin{array}{l}\text { Base } \\
\text { dados }\end{array}$ & $\begin{array}{c}\text { Total } \\
\text { encontrado via } \\
\text { descritores }\end{array}$ & $\begin{array}{c}\text { Eliminação } \\
\text { duplicados na } \\
\text { junção das bases }\end{array}$ & $\begin{array}{c}\text { Eliminados após } \\
\text { leitura Título e } \\
\text { Resumo }\end{array}$ & $\begin{array}{c}\text { Amostra final } \\
\text { resultante por } \\
\text { base }\end{array}$ \\
\hline DOAJ & 26 & 2 & 3 & 21 \\
\hline Redalyc & 17 & 3 & 11 & 3 \\
\hline Scielo & 22 & 5 & 2 & 15 \\
\hline Scopus & 11 & 1 & 3 & 9 \\
\hline Spell & 20 & 7 & 4 & $\mathbf{5 5}$ \\
\hline Total & $\mathbf{9 6}$ & $\mathbf{1 8}$ & $\mathbf{2 3}$ & \\
\hline
\end{tabular}

Fonte. elaborada pelos autores (2020)

Composta a amostra final, realizou-se a leitura integral das publicações e passou-se para a apresentação dos resultados e as discussões.

\section{RESULTADOS E DISCUSSÃO}

Para melhor visualização dos resultados, optou-se por apresentá-los organizados em subseções.

\section{Publicações por Ano}

Na Tabela 2 apresenta-se a distribuição cronológica ano a ano, das publicações dos artigos da amostra.

Tabela 2. Levantamento da amostra por ano

\begin{tabular}{c|c|c}
\hline Ano & Frequência absoluta & Frequência relativa \\
\hline 2006 & 2 & 3,64 \\
\hline 2008 & 1 & 1,82 \\
\hline 2009 & 2 & 3,64 \\
\hline 2010 & 2 & 3,64 \\
\hline 2011 & 1 & 1,82 \\
\hline 2012 & 2 & 3,64 \\
\hline 2013 & 5 & 9,09 \\
\hline 2015 & 4 & 7,27 \\
\hline 2016 & 12 & 21,82 \\
\hline 2017 & 4 & 7,27 \\
\hline 2018 & 6 & 10,91 \\
\hline 2019 & 8 & 14,55 \\
\hline 2020 & 6 & 10,91 \\
\hline total & $\mathbf{5 5}$ & $\mathbf{1 0 0 , 0 0}$ \\
\hline
\end{tabular}

Fonte. elaborada pelos autores (2020)

A distribuição contempla os anos de 2006 a 2020, com uma produção científica oscilante, apresentando a maior frequência, sobre a temática, no ano de 2016. O fator que pode justificar esta frequência de publicações em 2016 remete às mudanças de governo, devido a problemas na gestão fiscal do governo Dilma Roussef, quando o então vice-presidente da República, Michel Temer (MDB), assumiu a presidência interinamente. Outro fator relevante a ser considerado pode ter sido a extinção da Controladoria Geral da União (CGU), pela Lei no 13.341/2016, e a criação do 
Ministério da Transparência, Fiscalização e Controladoria-Geral da União, que passou a assumir o status de ministério.

\section{Classificação Metodológica: Abordagem das Pesquisas}

Em continuidade à análise, considerou-se a classificação quanto à abordagem utilizada nas pesquisas sobre transparência em portais eletrônicos dos artigos da amostra, conforme expõe a Tabela 3.

Tabela 3. Classificação quanto à abordagem das pesquisas

\begin{tabular}{c|c|c}
\hline Classificação quanto à natureza & Frequência absoluta & $\%$ \\
\hline Não identificada & 13 & 23,64 \\
\hline Quantitativa* & 12 & 21,82 \\
\hline Identificadas quantitativas** & 12 & 21,82 \\
\hline Qualitativa & 8 & 14,55 \\
\hline Quali-quanti & 6 & 10,91 \\
\hline Quanti-quali & 4 & 7,27 \\
\hline Total Geral & 55 & 100,00
\end{tabular}

*Os artigos declaravam utilizar abordagem quantitativa

** Os artigos não declaravam utilizar abordagem quantitativa mas utilizaram abordagem quantitativa

Fonte. elaborada pelos autores (2020)

Ressalta-se que, em 23,64\% dos artigos, não se identificou a abordagem da pesquisa, e que $21,82 \%$ dos artigos foram identificados como quantitativos, pois apresentavam a aplicação de técnicas estatísticas. Assim, a abordagem quantitativa evidenciada representou $43,64 \%$ dos métodos utilizados nos artigos. Percebeu-se a utilização de abordagem qualitativa-quantitativa e quantitativa-qualitativa nos artigos devido à importância de se avaliar a qualidade da informação pública disponibilizada no sítio; bem como foram observadas as análises das diferentes legislações, além da busca por mensurar a qualidade por meio da elaboração de índices que utilizam parâmetros quantificáveis que justificam estas abordagens.

\section{Frequência de Publicações por Periódicos/Bases de Dados}

Dos periódicos indexados pelas bases de dados utilizadas neste estudo, destacaram-se: na DOAJ, a Revista Controle Doutrinas e Artigos e a Revista Catarinense da Ciência Contábil - CRCSC com, respectivamente, 2 e 3 publicações; na Scopus, a revista Espacios.com apresentou 2 publicações; na Scielo, teve 3 publicações da Revista Administração Pública - RAP; e na Spell, através da revista Administração Pública e Gestão Social ocorreram 2 publicações. Observa-se que a maioria dos periódicos que publicaram este tema são revistas da área de Contabilidade, como a Revista Catarinense de Ciência Contábil - CRCSC, que apontou mais de 3 artigos indexados numa mesma base de dados. No mais, ressalta-se, ainda, a observância de baixa indexação por periódico referente ao tema, sugerindo pouca abrangência do tema nos periódicos e lacunas a serem exploradas.

\section{Análise de Conteúdo}

Diante das possíveis lacunas sobre o tema do presente artigo e, com a finalidade de confirmar e aprofundar o conhecimento, aplicou-se a análise de conteúdo aos 55 
artigos da amostra final, que, de forma sintetizada, foi classificada e se expõe na Tabela 4.

Tabela 4. Síntese da análise de conteúdo dos artigos da amostra final

\begin{tabular}{|c|c|c|c|}
\hline Bases & Frequência & $\begin{array}{c}\text { Total por } \\
\text { objetivo }\end{array}$ & Categoria \\
\hline $\begin{array}{l}\text { DOAJ } \\
\text { Scopus } \\
\text { Scielo } \\
\text { Speel } \\
\text { Redalyc }\end{array}$ & $\begin{array}{c}10 \\
5 \\
11 \\
4 \\
1 \\
\end{array}$ & 31 & $\begin{array}{l}\text { a) relacionam à elaboração, análise, } \\
\text { identificação e avaliação de transparência } \\
\text { governamental e fiscal em portais eletrônicos, } \\
\text { em consonância com o controle social. }\end{array}$ \\
\hline $\begin{array}{c}\text { DOAJ } \\
\text { Spell }\end{array}$ & $\begin{array}{l}4 \\
2\end{array}$ & 6 & $\begin{array}{l}\text { b) relacionam à transparência fiscal em portais } \\
\text { eletrônicos governamental, e à } \\
\text { correlação/associação com legislação e os } \\
\text { indicadores socioeconômicos e outros } \\
\text { indicadores. }\end{array}$ \\
\hline $\begin{array}{l}\text { DOAJ } \\
\text { Scopus } \\
\text { Scielo } \\
\text { Spell }\end{array}$ & $\begin{array}{l}7 \\
2 \\
4 \\
2\end{array}$ & 15 & $\begin{array}{l}\text { c) analisam a transparência em portais } \\
\text { eletrônicos governamentais a partir do } \\
\text { cumprimento da legislação vigente existente, ou } \\
\text { seja, compliance. }\end{array}$ \\
\hline $\begin{array}{c}\text { Redalyc } \\
\text { Speel }\end{array}$ & $\begin{array}{l}2 \\
1\end{array}$ & 3 & $\begin{array}{l}\text { d) relacionam à transparência em portais } \\
\text { eletrônicos governamentais com prestação de } \\
\text { contas e accountability. }\end{array}$ \\
\hline \multicolumn{2}{|l|}{ Total geral } & 55 & \\
\hline
\end{tabular}

Fonte. elaborada pelos autores (2020)

Com a análise do conteúdo dos artigos na íntegra, conseguiu-se construir quatro categorias (Tabela 4), que contemplaram os temas e as abordagens dos 55 artigos sobre transparência de portais eletrônicos governamentais. Com a classificação por categorias, evidencia-se que, na categoria (d), que relaciona a transparência em portais eletrônicos governamentais em relação à prestação de contas e accountability, foram identificados 03 (três) artigos, demonstrando que a transparência em portais eletrônicos do governo ainda não está dispensando a devida atenção para a accountability e prestação de contas, conforme demonstra, também, no estudo de Raupp e Pinho (2012).

No caso da categorização (b) e (c), foram encontrados 21 (vinte e um) artigos, sendo que, na primeira categorização observou-se haver níveis baixos entre transparência fiscal eletrônica, conflitando com o desenvolvimento socioeconômico. Contudo, por outro lado, as variáveis população, receita orçamentária, taxa de alfabetização, IDH-M, IQM e estágio do sítio apresentam uma relação positiva e significativa com a transparência fiscal eletrônica, corroborando os estudos de Cruz et al. (2012).

No caso da aplicabilidade do regramento legal quanto ao cumprimento de transparência, observa-se que não houve, ainda, uma devida adequação nos portais eletrônicos quanto à informação e à divulgação dos aspectos exigidos nas legislações existentes (Lei de Acesso à Informação, Lei de Responsabilidade Fiscal - LRF, entre outras), conforme também identificado nos estudos de Comin et al. (2016) e Nunes et al. (2013).

Desse modo, por representar a atuação da transparência em portais eletrônicos governamentais a partir da construção, análise, avaliação e medição de indicadores que possam avaliar, identificar e instrumentalizar com parâmetros de transparência em 
consonância com o controle social e a democracia, considera-se a Categoria (a) (a primeira exposta na Tabela 4), com seus 31 artigos, o foco principal do presente estudo. Nesse caso, evidencia-se a necessidade de utilizar a aplicação, análise e identificação das informações, que devem ser disponibilizadas, com a demonstração ou formulação de variáveis capazes de mensurar e avaliar o grau da transparência com base nos portais governamentais.

Diante disso, ao concentrar a análise nos artigos dessa última categoria (a), percebeu-se consenso de que a transparência nos portais não é apresentada de forma eficaz, o que inviabiliza sua capacidade de proporcionar interação entre as ações desenvolvidas pela administração pública e, inclusive, inviabilizando até a compreensão por quem acompanha tais informações. Essa constatação corrobora os achados de Raupp, Abreu e Abreu (2015) que, em seus estudos sobre transparência em municípios, concluíram que, se a disponibilidade das informações ainda não é tangível, fica prejudicada a constituição de transparência. Por seu turno, Santana Jr. et al. (2009) sugerem que medidas e ações governamentais devem ser tomadas como forma de aliviar os problemas referentes à ineficiente transparência fiscal eletrônica em relação ao que determina a legislação.

Outra evidência remete a que a maioria dos estudos abrangendo a transparência em portais governamentais está na esfera municipal, tanto no executivo como no legislativo, mesmo em pesquisas em outros países, de forma a atribuir como esses municípios se comportam na disseminação das informações em seus portais, possibilitando, assim, a participação e ampliação popular na aplicação da democracia.

Percebe-se, especificamente no artigo de Allegretti e Platt Neto (2010), a existência de uma dispersão das informações nos sítios eletrônicos, o que dificulta o acesso, e faz com que a transparência nos portais não proporcione uma interação da sociedade com a administração pública, por meio das ações dos gestores.

É perceptível, na maioria dos estudos analisados, a utilização de parâmetros/indicadores, como acessibilidade, conteúdo, usabilidade, informações financeiras, entre outros, compondo a formação de escala de pontuação para cada elemento, a ser aplicada na mensuração de um índice de desempenho da transparência em portais eletrônicos governamentais, metodologia que se assemelha ao método proposto por Martindel, descrito por Hourneaux Jr., Ruiz e Corrêa (2005).

\section{Autores mais Citados pelas 31 Publicações da Categoria (A)}

Com o intuito de identificar as publicações mais relevantes dentre as 31 , utilizou-se do Google Scholar para identificar os mais citados, conforme ilustra a Tabela 5 .

Tabela 5. Artigos mais citados em ordem decrescente nas 31 publicações da categoria (a)

\begin{tabular}{c|c|l|c}
\hline Autores & Ano & \multicolumn{1}{|c}{ Título } & $\begin{array}{c}\text { Número de } \\
\text { citações }\end{array}$ \\
\hline $\begin{array}{c}\text { Cruz; Ferreira; Silva; } \\
\text { Macedo }\end{array}$ & 2012 & $\begin{array}{l}\text { Transparência da gestão pública municipal: } \\
\text { um estudo a partir dos portais eletrônicos } \\
\text { dos maiores municípios brasileiros }\end{array}$ & 221 \\
\hline Bairral; Silva; Alves & 2015 & $\begin{array}{l}\text { Transparência no setor público: uma } \\
\text { análise dos relatórios de gestão anuais de } \\
\text { entidades públicas federais no ano de 2010 }\end{array}$ & 100 \\
\hline Arauijo; Tejedo-Romero & 2016 & $\begin{array}{l}\text { Índice de transparência dos governos } \\
\text { locais: determinantes da classificação dos }\end{array}$ & 83 \\
\hline
\end{tabular}




\begin{tabular}{|c|c|c|c|}
\hline & & municípios & \\
\hline Braga; Nicolás & 2008 & $\begin{array}{l}\text { Prosopografia a partir da web: avaliando e } \\
\text { mensurando as fontes para o estudo das } \\
\text { elites parlamentares brasileiras na internet }\end{array}$ & 37 \\
\hline Souza;Barros;Araújo;Silva & 2013 & $\begin{array}{l}\text { Índice de transparência municipal: um } \\
\text { estudo nos municípios mais populosos do } \\
\text { Rio Grande do Norte }\end{array}$ & 36 \\
\hline Abdala; Torres & 2016 & $\begin{array}{l}\text { A Transparência como espetáculo: uma } \\
\text { análise dos portais de transparência de } \\
\text { estados brasileiros }\end{array}$ & 30 \\
\hline Prado & 2006 & $\begin{array}{l}\text { Agências reguladoras e transparência: a } \\
\text { disponibilização de informações pela } \\
\text { Aneel }\end{array}$ & 28 \\
\hline Allegretti; Platt Neto & 2010 & $\begin{array}{l}\text { Funcionalidades, limitações e } \\
\text { potencialidades do portal da transparência } \\
\text { do Estado do Rio Grande do Sul }\end{array}$ & 15 \\
\hline $\begin{array}{c}\text { Raupp; Abreu E.; Abreu } \\
\text { M. }\end{array}$ & 2015 & $\begin{array}{l}\text { Disponibilização de informações à } \\
\text { sociedade em meios eletrônicos: um estudo } \\
\text { nas prefeituras dos maiores municípios } \\
\text { brasileiros }\end{array}$ & 13 \\
\hline Araújo; Reis; Sampaio. & 2016 & $\begin{array}{l}\text { A transparência e os dados abertos andam } \\
\text { juntos? Uma análise de iniciativas em } \\
\text { cinco capitais brasileiras }\end{array}$ & 12 \\
\hline Zuccolotto; Teixeira & 2015 & $\begin{array}{l}\text { Gestão social, democracia, representação e } \\
\text { transparência: evidências nos estados } \\
\text { brasileiros }\end{array}$ & 9 \\
\hline $\begin{array}{l}\text { Martínez-Rolán; Piñeiro- } \\
\text { Otero; Baamonde-Silva }\end{array}$ & 2016 & $\begin{array}{l}\text { O desafio e transparência na comunicação } \\
\text { digital: um estudo de caso nos sites } \\
\text { municipais da Galiza e norte de Portugal }\end{array}$ & 9 \\
\hline Tejedo-Romero; Araujo & 2018 & $\begin{array}{l}\text { Transparência nos municípios espanhóis: } \\
\text { determinantes da divulgação de } \\
\text { informações }\end{array}$ & 9 \\
\hline $\begin{array}{l}\text { Rodríguez; Gomez; } \\
\text { Hernández }\end{array}$ & 2017 & $\begin{array}{l}\text { Medindo a transparência do governo local: } \\
\text { Influência de signo político em análise } \\
\text { multidimensional }\end{array}$ & 8 \\
\hline Anissa; Ritonga. & 2018 & $\begin{array}{l}\text { Análise da transparência da gestão } \\
\text { financeira local em sites do governo local } \\
\text { em Jawa }\end{array}$ & 7 \\
\hline Heras; Agudo; Jalón & 2016 & $\begin{array}{l}\text { Analisando as transparências variáveis } \\
\text { tradicionais dentro os municípios } \\
\text { espanhóis }\end{array}$ & 6 \\
\hline $\begin{array}{c}\text { Matheus; Ribeiro; Vaz; } \\
\text { Souza }\end{array}$ & 2010 & $\begin{array}{l}\text { Usando a internet para promover a } \\
\text { transparência e combater corrupção: } \\
\text { portais de transparência América Latina }\end{array}$ & 5 \\
\hline Martín, Simelio; Amparo. & 2017 & $\begin{array}{l}\text { Acesso à web para pessoas com } \\
\text { habilidades limitadas em municípios } \\
\text { espanhóis }\end{array}$ & 4 \\
\hline Visentini; Santos & 2019 & $\begin{array}{l}\text { Transparência na gestão pública municipal } \\
\text { evidenciada nos portais eletrônicos dos } \\
\text { municípios do Conselho Regional de } \\
\text { Desenvolvimento (Corede) das } \\
\text { Missões/RS }\end{array}$ & 3 \\
\hline
\end{tabular}




\begin{tabular}{|c|c|c|c|}
\hline $\begin{array}{l}\text { Ciucci; Diaz; Alderete; } \\
\text { Linares }\end{array}$ & 2019 & $\begin{array}{l}\text { Construção de um index para medir a } \\
\text { transparência municipal: Buenos Aires, } \\
\text { Bahía Blanca e as capitais de província da } \\
\text { Argentina }\end{array}$ & 2 \\
\hline Melo; Fuchigami & 2019 & $\begin{array}{l}\text { Proposta de índice bidimensional de } \\
\text { transparência da informação público- } \\
\text { eletrônica como ferramenta para } \\
\text { participação e controle sociais }\end{array}$ & 1 \\
\hline Diniz; Machado; Matos & 2016 & $\begin{array}{l}\text { Transparência digital na gestão pública: } \\
\text { uma análise de conglomerados nos } \\
\text { municípios cearense }\end{array}$ & 1 \\
\hline $\begin{array}{l}\text { Campagnoni; Carvalho; } \\
\text { Lyrio; Lunkes; Rosa }\end{array}$ & 2016 & $\begin{array}{l}\text { Transparência no poder legislativo } \\
\text { municipal: uma análise dos portais } \\
\text { eletrônicos das câmaras de vereadores das } \\
\text { capitais brasileiras }\end{array}$ & 1 \\
\hline $\begin{array}{l}\text { Cole; Lyrio; Lunkes ; } \\
\text { Lima }\end{array}$ & 2017 & $\begin{array}{l}\text { Transparência pública mediada por } \\
\text { computadores: como estão os ministérios } \\
\text { de Moçambique à luz da legislação }\end{array}$ & 1 \\
\hline Seguro; Cano; Rodriguez & 2018 & $\begin{array}{l}\text { Transparência ativa, sua relação com área } \\
\text { de governo: caso de administrações } \\
\text { público territorial na Colômbia }\end{array}$ & 1 \\
\hline Nebot, Carmen Pineda & 2019 & $\begin{array}{l}\text { Transparência nas aquisições públicas } \\
\text { locais dos conselhos de cidade do país } \\
\text { basco (Espanha) }\end{array}$ & 1 \\
\hline $\begin{array}{l}\text { Antonello; Dias; Jacovetti; } \\
\text { Passos; Gaio; Brito; } \\
\text { Pereira } \\
\end{array}$ & 2016 & $\begin{array}{l}\text { Transparência da gestão fiscal em } \\
\text { municípios do estado de São Paulo - Brasil }\end{array}$ & 0 \\
\hline $\begin{array}{l}\text { Conesa; Martínez - } \\
\text { Martínez, Andrades; } \\
\text { Larran } \\
\end{array}$ & 2020 & $\begin{array}{l}\text { Fundações universitárias: um exame da } \\
\text { extensão e suas divulgações obrigatórias } \\
\text { em suas páginas da web }\end{array}$ & 0 \\
\hline $\begin{array}{l}\text { Sandoval-Almazan, } \\
\text { Rodrigo }\end{array}$ & 2019 & $\begin{array}{l}\text { Governo aberto e transparência em } \\
\text { México: estudo longitudinal 2015-2018 }\end{array}$ & 0 \\
\hline $\begin{array}{l}\text { Araújo; Kronbauer; } \\
\text { Carvalho; Cirne }\end{array}$ & 2020 & $\begin{array}{l}\text { Quem está ficando para trás? Uma análise } \\
\text { da transparência pública dos portais } \\
\text { eletrônicos de municípios tocantinenses }\end{array}$ & 0 \\
\hline $\begin{array}{l}\text { Diaz; González; Romero; } \\
\text { Chavez. }\end{array}$ & 2019 & $\begin{array}{l}\text { Avanços de transparência de dados ativos e } \\
\text { abertos em governos locais: o caso de } \\
\text { Coquimbo e La Serena, no Chile }\end{array}$ & 0 \\
\hline
\end{tabular}

Fonte. elaborada pelos autores (2020)

O artigo de Cruz et al. (2012), se comparado às outras publicações, destacou-se dos demais, uma vez que apresentou $54,03 \%$ do total de citações dentre os 31 estudos analisados. Esse elevado grau de citações pode ser justificado pela construção de uma metodologia estabelecida com base em códigos internacionais de boas práticas de transparência e governança na legislação brasileira, chamado de Índice de Transparência da Gestão Pública Municipal (ITGPM). Este estudo, assim como a maioria dos estudos nesta área de transparência em portais eletrônicos governamentais, estudou o âmbito municipal. 


\section{Redes de pesquisa}

Apresentadas as citações, acreditou-se importante que as redes de interação entre os 88 autores das 31 publicações selecionadas também fossem analisadas. Chama-se a atenção, nesse sentido, que as redes de pesquisa impulsionam a criação do conhecimento e o processo de inovação, resultantes do intercâmbio de informações; sobretudo, da junção de competências de grupos que unem esforços na busca de metas comuns. Nessa perspectiva, na Figura 1, demonstra-se o resultado da análise de redes sociais de colaboração realizada.

Figura 1. Análise de redes de pesquisa

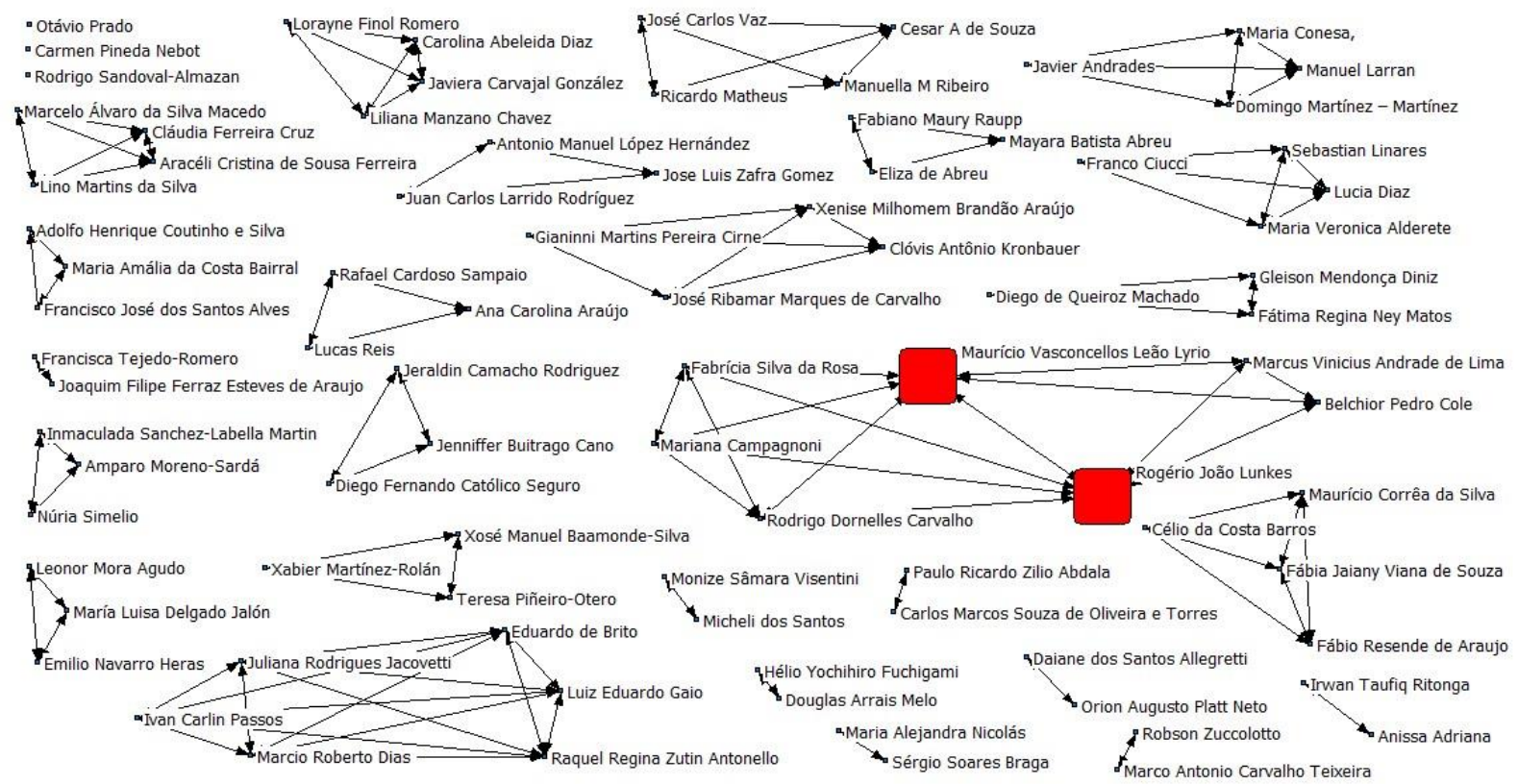

Fonte. elaborada pelos autores (2020)

Ao analisar as redes de pesquisa, observa-se a ocorrência de laços fortes e laços fracos entre autores. Cabe lembrar que laços fortes são caracterizados pela conexão direta dos atores em uma rede (GRANOVETTER, 1973). Assim, os laços fortes são interpretados na Figura 1, como todas as conexões existentes, exceto a rede com destaques em vermelho.

Justamente essa rede em destaque vermelho trata da ocorrência de laços fracos, cujos contatos são indiretos e formados por meio de pontes, o que, segundo Granovetter (1973), confere diferentes fontes de informação, oferecendo, portanto, vantagens aos esforços científicos. Como autores centrais nessa rede destacam-se o professor Rogério João Lunkes, Dr. do Departamento de Contabilidade da Universidade Federal de Santa Catarina (UFSC), e o Gerente de Transparência e Dados Abertos na ControladoriaGeral do Estado de Santa Catarina, Maurício Vasconcellos Leão Lyrio, Dr.

Os dois nós centrais da rede destaque além de favorecer o fluxo de informações entre redes que, sem eles, seriam isoladas, têm o maior número de relações e, assim o melhor capital social da rede apresentada, visto que, em virtude de suas conexões e posição na estrutura social, encontram maiores facilidades de acesso à informação, fato que, segundo Burt (1992), fornece uma vantagem competitiva em relação ao indivíduo que não realiza a conexão entre as diferentes redes. 


\section{CONSIDERAÇÕES FINAIS}

Conforme foi constituído o objetivo de mapear as produções científicas em transparência em portais eletrônicos governamentais, como resposta, evidenciou-se, na pesquisa, que as publicações referentes ao tema, no ano de 2016, obtiveram uma frequência de 26, 32\%, em relação às demais publicações nos anos apresentados.

Foi averiguado que os artigos quantitativos representaram $43,64 \%$ das abordagens utilizadas nos artigos.

Outra observação feita partiu da identificação da construção de uma análise do conteúdo da amostra dos 31 artigos, que resultou nas seguintes características: i) níveis inexpressivos de transparência nos portais analisados, e que isto prejudica o controle social e fiscal por parte da sociedade; ii) dispersão das informações nos sítios eletrônicos, dificultando o acesso às informações; iii) a maioria dos estudos foram referentes à transparência de portais governamentais municipais; e iv) existência da contribuição de metodologias voltadas para a elaboração do índice de transparência, de forma diversificada, com aplicação de vários tipos de categorias, variáveis e critérios.

Por fim, todas as análises indicaram existir sítios com uma diversificação de estruturas e nomenclaturas nos portais eletrônicos, o que pode dificultar o acesso do cidadão, corroborando estudo de Michener, Contreras e Niskier (2018). Assim, há possibilidade de desenvolvimento de estudos que possam avaliar e sugerir melhorias para a administração pública quanto a promoção da transparência em portais eletrônicos governamentais. Nesse sentido, sugere-se, para pesquisas futuras na temática, a ampliação para outras esferas governamentais, e das fontes pesquisadas.

Dessa maneira, a análise dos artigos apresentou a possibilidade de aplicação e adaptação de modelos, visando futuras pesquisas na esfera federal e estadual de governo, como novos indicadores que possam relacionar por meio da aplicação de escalas de pontuações e outras variáveis, ou ainda, no desenvolvimento de um modelo mais robusto, que demonstre a transparência nos portais eletrônicos governamentais.

\section{REFERÊNCIAS}

ABDALA, P. R. Z; TORRES, C. M. S. O. A Transparência como Espetáculo: uma análise dos portais de transparência de estados brasileiros. Administração Pública e Gestão Social, v. 8, n. 3, p. 147-158, 2016.

ALLEGRETTI, D. S.; PLATT NETO, O. A. Funcionalidades, limitações e potencialidades do portal da transparência do estado do Rio Grande do Sul. Revista Catarinense da Ciência Contábil, v. 9, n. 26, p. 79-95, abr./jun. 2010.

ANISSA, A.; RITONGA, I, T. Analysis of Local Financial Management Transparency Based on Websites on Local Government in Java. JDA Jurnal Dinamika Akuntansi, v. 10, n. 1, p. 13-26, 2018.

ANTONELLO, R. R. Z. et al. Transparência da gestão fiscal em municípios do estado de São Paulo - Brasil. Revista Espacios.com, v. 37, n. 26, p. 21, 2016.

ARAÚJO, A. C.; REIS, L.; SAMPAIO, R. C. Do Transparency and Open Data Walk Together? An Analysis of Initiatives in Five Brazilian Capitals. Medijske studije, v. 7, n. 14 , p. $65-82,2016$. 
ARAÚJO, X. M. B. et al. Quem está ficando para trás? Uma análise da transparência pública dos portais eletrônicos de municípios tocantinenses. Revista Contemporânea de Contabilidade - RCC, v. 17, n. 44, p. 123-141, jul./set., 2020.

BAIRRAL, M. A. C.; SILVA, A. H. C.; ALVES, F. J. S. Transparência no setor público: uma análise dos relatórios de gestão anuais de entidades públicas federais no ano de 2010. Revista de Administração Pública, v. 49, n. 3, p. 643-675, 2015.

BEIRA, J. C. et al. Indicadores bibliométricos na produção científica em periódicos brasileiros da ciência da informação no estrato A1. Revista ACB, v. 25, n. 2, p. 383408, jul. 2020.

BRAGA, S. S.; NICOLAS, M. A. Prosopografia a partir da web: avaliando e mensurando as fontes para o estudo das elites parlamentares brasileiras na internet. Revista de Sociologia e Política, v. 16, n. 30, p. 107-130, jun. 2008.

BURT, R. Structural Holes: The Social Structure of Competition. Cambridge, MA: Havard University Press, 1992.

CAMPAGNONI, M. et al. Transparência no Poder Legislativo Municipal: uma Análise dos Portais Eletrônicos das Câmaras de Vereadores das Capitais Brasileiras. Revista Gestão Organizacional, v. 9, n. 1, p. 21-42, 2016.

CIUCCI, F. et al. Construcción de un índice para medir la transparencia municipal: Buenos Aires, Bahía Blanca y las capitales de provincia de Argentina. Revista iberoamericana de estudios municipales, n. 20, p. 59-84, ago. 2019.

COLE, B. P. et al. Transparência Pública Mediada por Computadores: Como estão os ministérios de Moçambique à luz da legislação? Cadernos de Estudos Africanos, n. 34, p. 197-227, dez. 2017.

COMIN, D. et al. A transparência ativa nos municípios de Santa Catarina: avaliação do índice de atendimento à lei de acesso à informação e suas determinantes Revista Catarinense da Ciência Contábil, v. 15, n. 46, p. 24-34, nov. 2016.

CONESA, M. et al. University foundations: an examination of the extent of their mandatory disclosures on their webpages. Journal of Public Budgeting, Accounting \& Financial Management, v. 32, n. 4, p. 529-549, 2020.

CRUZ, C. F. et al. Transparency of the municipal public management: a study from the homepages of the large Brazilian municipalities. Revista de Administração Pública, v. 46, n. 1, p. 153-176, fev. 2012.

CRUZ, C. F.; SILVA, L. M.; SANTOS, R.Transparência da Gestão Fiscal: Um Estudo a partir dos Portais Eletrônicos dos Maiores Municípios do Estado do Rio de Janeiro. Journal of Accounting, Management and Governance, v. 12, n. 3, p. 102-115, set./dez. 2009.

CRUZ, G. J. L.; ZUCCOLOTTO, R. Transparência ativa no Judiciário: um estudo dos portais eletrônicos dos Tribunais de Justiça. Cadernos Gestão Pública e Cidadania, v. 25, n. 82, p. 1-21, 2020.

DINIZ, G. M.; MACHADO, D. Q.; MATOS, F. R. N. Transparência Digital na Gestão Pública: uma Análise de Conglomerados nos Municípios Cearenses. Revista Controle Doutrina e Artigos, v. 14, n. 2, p. 197-217, 31 dez. 2016. 
GAMA, J. R.; RODRIGUES, G. M. Transparência e acesso à informação: um estudo da demanda por informações contábeis nas universidades federais brasileiras. Revista Transformação, v. 28, n. 1, p. 47-57, jan./abr. 2016.

GRANOVETTER, M. The Strength of Weak Ties. American Journal of Sociology, v. 78, n. 6, p. 1360-1380, 1973.

HOURNEAUX JUNIOR, F.; RUIZ, F.M.; CORRÊA, H. A evolução dos métodos de mensuração e avaliação de desempenho das organizações. In: ENCONTRO DA ANPAD, 29, 2005, Brasília. Anais... Rio de Janeiro: ANPAD, 2005.

MATHEUS, R.; et al. Using the internet to promoting the transparency The Latin American Transparency Portals. In: INTERNACIONAL CONFERENCE ON THEORY AND PRACTICE OF ELECTRONIC GOVERNANCE, 4, 2010, Pequim. Proceedings of the 4th International Conference on Theory and Practice of Electronic Governance. Beijing: ICEGOV, 2010.

MEIJER, A. Understanding modern transparency. International Review Of Administrative Sciences, v. 75, n. 2, p. 255-269, jun. 2009.

MELO, D. A.; FUCHIGAMI, H. Y. Proposta de índice bidimensional de transparência da informação público-eletrônica como ferramenta para participação e controle sociais. Revista Eletrônica de Administração - Read, v. 25, n. 2, p. 179-214, maio/ago. 2019.

MICHENER, G.; CONTRERAS, E.; NISKIER, I. From opacity to transparency? Evaluating access to information in Brazil five years later. Revista de Administração Pública, v. 52, n. 4, p. 610-629, ago. 2018.

MORAIS, M. G. M.; GUERRA, L. C. B.. Lei de acesso à informação: uma análise dos portais e sítios eletrônicos oficiais das prefeituras do RN. EmpíricaBR - Revista Brasileira de Gestão, Negócio e Tecnologia da Informação, v. 1, n. 2, p. 85-104, jan. 2016.

NUNES, G. S. D. F. et al. Análise dos instrumentos de transparência contidos na Lei de Responsabilidade Fiscal nos municípios da região sul. Revista Ambiente Contábil, v. 5, n. 2, p. 128-150, 2013.

NEBOT, C. P. Transparencia en la contratación pública local de los ayuntamientos del País Vasco (España). Revista iberoamericana de estudios municipales, n. 20, p. 85111, ago. 2019.

PIRES, A. M. et al. Transparência da gestão pública municipal: um estudo dos municípios de Santa Maria e Novo Hamburgo / RS. Estudos do CEPE, n. 38, p. 131160, jan. 2013.

PRADO, O. Agências reguladoras e transparência: a disponibilização de informações pela Aneel. Revista Administração Pública, Rio de Janeiro, v. 40, n. 40, p. 631-646, 2006.

PRADO, O.; LOUREIRO, M. R. G. Governo eletrônico e transparência: avaliação da publicização das contas públicas das capitais brasileiras. Revista Alcance, v. 13, n. 3, p. 355-372, 2006.

RAUPP, F. M.; ABREU, E.; ABREU, M. B. Disponibilização de informações à sociedade em meios eletrônicos: um estudo nas prefeituras dos maiores municípios 
brasileiros. Revista Catarinense da Ciência Contábil, v. 14, n. 42, p. 41-54, ago. 2015.

RAUPP, F. M.; PINHO, J. A. G. de. Portais eletrônicos de câmaras localizadas em pequenos municípios catarinenses: murais de construção da prestação de contas, transparência e participação? Revista Pensar Contábil, v. 14, n. 53, p. 35-43, 2012.

ROBLES-LOPEZ, C. M.; ZAMORA-MEDINA, R. Transparencia online como bien intangible del sector público. Transinformação, v. 32, 2020.

SALGADO, C. C. R.; AIRES, R. F. F. Governo eletrônico no Rio Grande do Norte: uma avaliação de prefeituras municipais a partir de lei de acesso à informação. Perspectivas em Ciência da Informação, v. 22, n. 3, p.98-115, jul./set. 2017.

SANDOVAL-ALMAZAN, R. Gobierno abierto y transparencia en México: estudio longitudinal 2015-2018. Innovar, v. 29, n. 74, p. 115-131, 2019.

SANTANA JUNIOR, J. J. B.; et al. Transparência fiscal eletrônica: uma análise dos níveis de transparência apresentados nos sites dos poderes e órgãos dos Estados e do Distrito Federal do Brasil. Revista de Educação e Pesquisa em Contabilidade (REPeC), v. 3, n. 3, p. 62-84, dez. 2009.

SOARES, S. V.; PICOLLI, I. R. A.; CASAGRANDE, J. L. Pesquisa Bibliográfica, Pesquisa Bibliométrica, Artigo de Revisão e Ensaio Teórico em Administração e Contabilidade. Administração: Ensino e Pesquisa, v. 19, n. 2, p. 308-339, maio 2018.

SOUZA, F. J. V.; et al. da. Índice de transparência municipal: um estudo nos municípios mais populosos do Rio Grande do Norte. Revista de Gestão, Finanças e Contabilidade, v. 3, n. 3, p. 94-113, 2013.

VISENTINI, M. S.; SANTOS, M. Transparência na gestão pública municipal evidenciada nos portais eletrônicos dos municípios do Conselho Regional de Desenvolvimento (Corede) das Missões/RS. Revista Desenvolvimento em Questão, v. 17, n. 49, p. 158-175, 2019.

ZUCCOLOTTO, R.; TEIXEIRA, M. A. C. Gestão social, democracia, representação e transparência: evidências nos estados brasileiros. Revista de Ciências da Administração, v. 17, n. especial, p. 79-90, 2015. 